\title{
As vicissitudes da formação docente em serviço: a proposta reflexiva em debate
}

J ulio Groppa Aquino

Mônica Cristina Mussi

Universidade de São Paulo

Correspondência:

J ulio Groppa Aquino

Faculdade de Educação (EDF) - USP

Av. da Universidade, 308 - BI. A

05508-900 - São Paulo, SP

e-mail: groppaq@usp.br
Resumo

Este artigo tem por objetivo apresentar algumas das conclusões de uma investigação realizada junto a professores da Rede Municipal de Ensino de São Paulo que participam de grupos de formação em serviço, a fim de conferir visibilidade aos efeitos que a prática formativa concreta vem produzindo na profissionalidade docente. Destaca, em particular, as vicissitudes ocasionadas nesse grupo quando experienciam uma modalidade formativa contemporânea, pautada no modelo de formação reflexiva.

As idéias desenvolvidas no artigo inscrevem-se no campo conceitual da psicologia institucional. A partir desse enquadramento teórico, o texto trabalha com o pressuposto de que os recentes paradigmas de formação docente em serviço, ao serem operados por práticas formativas concretas, promovem novas possibilidades de experiência de si para os professores, conferindo novas figurações de subjetividade para os professores no tempo presente - professor-reflexivo, professor-autônomo, professor-investigativo. No interior de relações institucionalizadas, a vivência destas figurações é metabolizada pelos docentes, que produzem uma forma peculiar de reflexão, não vislumbrada na pauta dos programas de formação.

Instalados nas práticas concretas de formação em serviço, os professores produzem um tipo de reflexão particular que escapa dos objetos definidos no design formativo e do contorno reflexivo mapeado a priori. A reflexão tangível nas falas docentes narra o confronto desse protagonista com seu lugar instituído na profissão, problematizando o "dever ser" de seu ofício nos dias de hoje.

Palavras-chave

Formação em serviço - Reflexão - Subjetividade docente. 


\section{The in-service teacher educ ation: the reflective proposal in debate}

J ulio Groppa Aquino

Mônica Cristina Mussi

Universidade de São Paulo

Correspondence:

J ulio Groppa Aquino

Faculdade de Educação (EDF) - USP

Av. da Universidade, 308 - BI. A

05508-900 - São Paulo, SP

e-mail: groppaq@usp.br

\section{Abstract}

This article presents some of the findings of a study conducted with teachers from the public school system of São Paulo (capital), which take part in in-service teacher education groups. The purpose is to give visibility to the effects that the concrete formative practice has been producing upon teacher's professionality. The article highlights in particular the vicissitudes experienced by the group when exposed to a contemporary modality of teacher education based on the model of reflective education.

The ideas developed here belong to the conceptual framework of Institutional Psychology. From this theoretical framework, the text deals with the assumption that the recent paradigms in teacher education, when worked through concrete formative practices, promote new possibilities of self-experience to the teachers, endowing them at the present time with new images of subjectivity - reflective teacher, autonomous teacher, research teacher. Within institutionalized relations, the experience of those images is metabolized by the teachers, who produce a peculiar form of reflection not envisaged in the agenda of teacher education programs.

Teachers, entered in concrete practices of in-service education, produce a particular kind of reflection that escapes from the objects defined in the formative design and from the reflective borders traced a priori. The tangible reflection in the teacher's speeches tells of the clash between this agent and her attributed professional place, problematizing the "must be" of his craft nowadays.

Keyw ords

In-service education - Reflection - Teacher subjectivity. 
Nada ainda constitui um programa, mesmo o niilismo é um dogma.

E. M. Cioran

A profissão docente vem, nas últimas décadas, sendo confrontada com uma ordem tal de problematizações sobre os limites e possibilidades de sua ação que está a provocar um desassossego ímpar em seus protagonistas concretos.

Os códigos que tradicionalmente comandaram as práticas profissionais docentes e, em particular, aqueles que definiram formas peculiares de como se pensar professor - um certo "saber de si" - hoje parecem já não encontrar ressonância nas experiências cotidianas dos professores, impulsionando-os à árdua tarefa de se (re)posicionarem em relação aos modelos que até então prescreveram suas condutas profissionais.

Ainda que essas problematizações possam ser trazidas à baila por múltiplos fenômenos (segundo análises, por sua vez, também diversas), acentuaremos algumas circunstâncias no que se refere às novas exigências do ofício, com 0 intuito de analisar o desconforto atual que os professores experienciam e pelo fato particular de terem suscitado o fortalecimento de uma prática específica de interven ção na docência: a formação de professores em serviço, prática esta objeto de uma pesquisa empírica por nós levada a cabo e da qual extraímos as principais reflexões que serão apresentadas no presente artigo.

0 trabalho de investigação foi realizado junto a oito professores da Rede Municipal de Ensino de São Paulo, integrantes de "grupos de formação", nomenclatura original de modalidade formativa criada a partir de 1989 na gestão Luíza Erundina (1989-1992). Essa modalidade ainda permanece em vigor nas escolas municipais, reconhecida atualmente pelos professores como "horários coletivos".

Entre os objetivos centrais que nortearam a nova política educacional implantada na gestão Erundina, encontrava-se uma preocupação inédita com a formação contínua dos professo- res integrantes da rede municipal de ensino. Até então, de acordo com levantamento realizado por Fusari (1997), as iniciativas de formação docente em serviço organizadas pela Secretaria Municipal de Educação de São Paulo (SMESP) restringiram-se à participação de educadores em situações formativas pontuais (cursos, palestras, etc.), caracterizando-se, no geral, por um conjunto de ações descontínuas, parceladas, sem conexão entre si, e, ainda, com grande rotatividade de pessoas, condição esta que privilegiava 0 caráter imediatista de seus objetivos.

As modalidades formativas que se destacaram no período que antecedeu a "gestão popular" - como foi denominado o período em questão - compreendiam, portanto, situações de aperfeiçoamento, atualização e mesmo treinamento como eventos marcados pela concisão. Mesmo quando o tempo de duração dessas ações formativas era ampliado ou seus espaços descentralizados, ocorrendo no espaço de trabalho original do professor, perduraram razões de cunho pragmático entre seus objetivos centrais.

De uma forma que consideramos singular, a ênfase dada à formação de professores na Rede Municipal de Ensino na referida administração esteve associada a uma perspectiva mais ampla do processo educativo escolar. 0 projeto central que conduziu aos investimentos na formação em serviço esteve, desde sua origem, comprometido com a concretização de uma "escola pública popular e democrática de boa qualidade" (Saul, 1993), pela via do necessário desenvolvimento profissional nos que nela trabalham, articulando de forma decisiva a reorientação da democratização escolar com a formação contínua de professores.

Dentre os projetos de formação que foram concretizados nesse período, 0 "grupo de formação" destacou-se por privilegiar o trabalho em pequenos grupos e, mais adiante, por se firmar no espaço cotidiano da escola. A SMESP à época concebeu a organização desse 
espaço formativo sustentada em premissas que sublinhavam a imagem do professor como um sujeito reflexivo.

Alguns trechos do documento oficial da SMESP são explícitos quanto a esse enfoque:

um dos princípios básicos do grupo de formação é 0 de que o sujeito constrói o conhecimento na interação com os outros através do estudo da prática de seu trabalho e da teoria que a fundamenta. Esse sujeito cognitivo, afetivo e social é uma totalidade que, imerso em seu trabalho, exercita o fazer, o pensar e o teorizar, pois não existe prática sem teoria. Todo educador faz teoria e prática. $(1990$, p. 9)

E continua, mais adiante:

Nos grupos de formação o educador pode encontrar o espaço necessário para refletir sobre sua prática e seus conhecimentos. A teoria pode ser elucidada, resgatada, apropriada, na relação dialética com a prática. É fundamental que o grupo de formação possibilite ao educador retomar a sua história, percebendo quais as hipóteses que teve durante sua vida de educador, e no que ele acredita hoje; quais são as contradições entre o seu pensar e dos outros. 0 grupo de formação não é o único meio para o despertar da consciência do educador, mas é um meio para isso se dar de forma sistematizada. Partindo do trabalho diário significativo dos educadores, favorece a percepção do cotidiano dessa prática. No grupo, a diversidade de leituras do cotidiano apura o olhar para ver além das aparências. Nesse processo político de apropriação da consciência pedagógica fundamenta-se o processo de mudança. 0 educador percebe que faz prática e teoria. Com essa descoberta pode educar o próprio desejo e alicerçar sua opção. Ele pode querer e fazer mudança. (SMESP, p. 9-10)

Desta feita, privilegiamos em nossa pesquisa práticas de formação em serviço que, em sua proposta formal, estivessem referenciadas pelos discursos teóricos que concebem o professor como um profissional reflexivo, em contraposição às concepções que circunscreveram a prática docente ao exercício "técnico" de saberes, entendendo esta última posição segundo um enquadramento discursivo que cinde a ação prática da ação refletida desse protagonista.

$\mathrm{Na}$ referida pesquisa propusemo-nos a investigar as representações que os professores produziam ao se inserirem em práticas de formação em serviço originárias dessa concepção. Mais especificamente, nosso objetivo foi 0 de descrever e analisar os efeitos que essa prática vem produzindo na profissionalidade docente atualmente.

Para proceder a esse objetivo, optamos por uma metodologia de pesquisa que se ajustasse às pautas de análise que indicamos perscrutar o movimento das práticas formativas e seus ef eitos no discurso docente. Assim, realizamos entrevistas gravadas e posteriormente transcritas, adotando como referente básico a formulação de um roteiro de questões, articuladas em torno de quatro categorias temáticas: 1) a formação inicial; 2) a opção pelos "grupos de formação": finalidades e funcionamento; 3) os efeitos dos "grupos de formação": implicações para a sala de aula; e 4) os "grupos de formação" e a relação entre seus protagonistas.

Como enfatizaremos adiante, a prática de formação de professores em serviço, em seu (re)arranjo epistemológico recente, produzirá em seu curso efeitos desestabilizadores das formas tradicionalmente reconhecidas de existência docente, operando a promessa de uma nova proposição de si, para os professores, nos nossos dias.

É a ocasião desses efeitos, rastreados no discurso dos professores entrevistados, que permeará o percurso das análises que ora apresentamos, o que evidencia e justifica a necessidade de se colocar a formação docente em serviço, na proposta reflexiva, em debate. 
O professor e a universalização das práticas escolares

Uma das razões que deflagraram um conjunto de demandas inéditas no interior da profissão docente na atualidade pode ser localizada na atual crise de legitimidade da instituição escolar na esfera social (Silva, 1996; Hargreaves, 1998).

No campo externo à profissão, protagonizado em particular pelo âmbito das instituições acadêmicas, sindicais e de alguns setores políticos, essa crise inscreveu-se por meio da denúncia de uma renitente exclusão da população aos bens culturais difundidos pela prática educativa escolar.

Em sua configuração escolar, a exclusão não só refreou a plena apropriação por parte de crianças e adolescentes dos bens culturais $a b$ sorvidos pela escola, como também vem produzindo roupagens inéditas para seu inventário. A duvidosa qualidade dos processos de ensino desencadeados no interior da prática institucional escolar parece ser a face revigorada desse potencial excludente.

A denúncia reincidente sobre a produção de mecanismos de exclusão de uma parcela significativa da população ao direito social à educação escolarizada, seja essa produção asseverada pelos índices de repetência e evasão escolar alardeados nas pesquisas das décadas de 1970-80, seja, em seu formato mais recente, localizada na baixa qualificação das formas de aprendizagem escolar imputada àqueles que vêm conseguindo concluir a trajetória formal na instituição, compõe um dos cenários de desordem em que as práticas escolares foram lançadas na contemporaneidade brasileira.

As rachaduras dessa desordem não tardarão a atingir o patamar docente, donde as pressões e demandas sobre o desempenho de seu ofício irão se mostrar por meio da invenção de novos modelos formativos para a profissão. A legitimidade assegurada da competência docente, ao ser interseccionada pela demanda de uma maior qualificação, é rearranjada por discursos que inauguram uma nova exigência profissionalizante para o ofício: uma vivência distinta dos modelos disponíveis até então no cenário formativo docente.

Já no campo interno da profissão, ou seja, para seus protagonistas concretos, localizamos uma segunda razão que incitaria um conjunto de demandas diversificadas para a profissão no presente, qual seja: a despotencialização dos saberes em que os professores assentavam suas condutas de trabalho.

Essa despotencialização traduz-se especialmente pela perda de segurança dos professores no que concerne àqueles conhecimentos canônicos sobre os quais estava fundada secularmente a prática do ensino escolar. Perda esta que, em específico, encontra sustentação no bojo do colapso das certezas científicas, precipitado na contemporaneidade pelos inúmeros problemas de ordem social e política vividos pelas populações mundiais (Demo, 1996; Veiga- Neto, 1995).

No cotidiano do trabalho escolar, a despotencialização dos saberes docentes é pressentida concretamente pela "incapacidade", autoproclamada pelos professores, de desempenhar seu ofício quando clivado por um perfil de clientela que não mais corresponde às representações clássicas daquilo que se aprendeu a compreen der e legitimar como características substantivas do alunado.

0 processo de expansão dos níveis de ensino e das oportunidades educativas na realidade brasileira, sancionado a partir da década de 1970, ocasionou uma fissura no suposto "equilíbrio" apregoado entre a formação profissional disponível e as demandas oriundas das salas de aula, deflagrando um grau sensível de abatimento sobre os docentes; fato este que interroga os modelos operativos com os quais os professores tradicionalmente vinham desempenhando em seu dia-a-dia profissional.

Esses modelos parecem, pois, não mais encontrar ressonância numa imagem de 
clientela que se desprende dos contornos anteriormente definidos para seu lugar institucional, defrontando-se agora com um aluno que passa a se apresentar de acordo com uma multiplicidade de rostos e formas, um aluno que já não comportaria uma sensibilidade a priori em relação às promessas de emancipação futura, propaladas pela escola da modernidade (Forquin, 1993; Silva, 1996). Proceder com dedicação aos rituais de aula (registros, leituras, atenção, etc.) em prol da promessa de uma profissão virtuosa, ou exercer a responsabilidade estudantil como forma primeira de se habilitar a uma cidadania autônoma na condição adulta, não mais se mostram como ações corporificadas pelo aluno atual; estas agora necessitam ser negociadas, contratualizadas e (re)inventadas (Aquino, 2000).

Esse dado pode ainda ser conjugado com a notória perda de status social da profissão e com a descaracterização paralela de sua autoridade intelectual/pedagógica/moral, seja na esfera intra-escolar, em meio ao descrédito emanado da própria clientela, seja por outros âmbitos institucionais, como a família e o poder público, os quais, décadas antes, comungaram mais diretamente com o enaltecimento da profissão.

Em meio a essas razões, o professor foi lançado num terreno profissional incerto, arenoso, repleto de efeitos desconhecidos na feitura dia a dia de seu ofício.

Uma das propostas firmadas como medida do poder público com vistas à requalificação da ação escolar foi a formação docente em serviço.

Que novas elaborações a formação docente em serviço trouxe para o professor em sua história presente?

Aproximemo-nos desse instigante contexto.

A formação docente em serviço

A multiplicidade de entraves na ação docente e os resultados socialmente questionáveis da prática escolar figuram como os motivadores fundamentais da expansão e valorização da formação profissionalizante no interior da prática educativa, provocando uma nova interpretação dos modelos disponíveis segundo os quais a formação profissional do professor fora até então demarcada, temporal e espacialmente.

Assistimos, nesse contexto, a um remodelamento das práticas de formação docente em vigor no cenário da profissão. De um modelo formativo instalado num intervalo de tempo anterior ao ingresso no exercício ef etivo da profissão e que se organizava em âmbitos distintos daquele que seria seu locus de trabalho, instauraram-se práticas formativas docentes que passam a ocorrer justapostas à experiência do ofício e, mais recentemente, no próprio local de trabalho.

Essas práticas, de uma maneira geral, passam a ser reconhecidas e nomeadas na realidade brasileira como "formação docente em serviço".

Os cursos de treinamento, nomenclatura largamente adotada para os espaços de formação em serviço, são os primeiros a ocupar lugar definido em nossa realidade, e, em sua imensa maioria, organizam-se com o objetivo de divulgar métodos e técnicas de trabalho concebidos como meios eficazes para o alcance de resultados satisfatórios nos processos de ensino.

Prática enunciada. A partir daí, intensifica-se a organização de novos programas formativos para professores. Aperfeiçoamento, capacitação, formação permanente são expressões das várias modalidades segundo as quais a prática de formação em serviço foi se apresentando no cotidiano escolar (Barbieri, Carvalho \& Uhle, 1995).

A formação concomitante ao exercício do ofício inaugura, assim, uma nova racionalização da profissionalidade, e, por extensão, da constituição dos saberes docentes. De um ponto de vista teórico, tratava-se de um 
dispositivo tático que fez circular, de forma mais precisa e localizada no interior da profissão, modos de se pensar professor.

Pode-se afirmar que, a princípio, o objetivo principal desse novo modelo regulador da formação - a formação em serviço - foi o de funcionar como uma espécie de "corretivo" das práticas docentes (Fusari, 1988). 0 efeito ensejado, presume-se, seria o de promover uma certa homogeneização, dessa vez mais controlada, das condutas cotidianas dos professores.

Nessa perspectiva, seu alvo maior seria a retomada da própria legitimidade da instituição escolar pelo controle mais estreito das atividades docentes; em outras palavras, revigorar a positividade e a confiança nos resultados escolares, ou seja: conferir fôlego à função social da escola, pela modulação permanente antes alocada exclusivamente na região da formação inicial das condutas de seus agentes.

Validar determinados procedimentos de trabalho, divulgar saberes utilitários para a prática cotidiana de suas tarefas, alterar ou constranger comportamentos considerados desajustados ao ofício, enfim, fazer circular um conjunto de modelos teóricos/metodológicos que assegurassem respostas confiáveis para as problemáticas vividas no âmbito da sala de aula, compunham o quadro desse controle. A formação em serviço passa, assim, a ter presença constante no exercício da profissão, acionada sempre que os mandantes institucionais julgassem necessário dispô-la.

Nesse sentido, a formação em serviço operou uma dilatação dos mecanismos de poder sobre a profissão, ao funcionar como campo de validação dos tipos de saber que deveriam circular no exercício mesmo da docência, indicando gradualmente maneiras de se proceder no ofício. Um outro efeito ensejado, talvez, fosse o de anular qualquer proposição de dúvida ou estado de esmorecimento que acompanhasse o professor na rotina de seu posto. Este deveria apresentar-se seguro e convicto daquilo que deveria ser, dizer e fazer em seu cotidiano profissional.
$\mathrm{Na}$ atualidade, a invenção de novas formas de formação docente concomitantes ao exercício da profissão vem, no plano discursivo, produzindo outras estratégias de existência para o professor, as quais não se apresentam necessariamente como ressonância ao objetivo primeiro de "correção" do ofício.

No final da década de 1970, a abordagem tecnicista de educação, que regia grande parte dos programas de formação de professores em serviço, é colocada sob suspeita. A suposta eficácia da racionalidade técnica passa a se confrontar diretamente com a fragilidade e as mazelas concretas dos resultados obtidos pelas práticas escolares (Fusari, 1988).

Protagonizada pelas ciências sociais (particularmente a vertente marxista), uma nova tendência na pesquisa educacional deflagra a crítica à crença em uma escola redentora da sociedade, denunciando o papel desta como reprodutora das relações de desigualdade impingidas no campo das relações econômicas e políticas.

Sob um olhar deterministo-reprodutivista, as relações escolares mimetizariam as práticas econômicas hegemônicas, sofrendo 0 mesmo grau de submissão instalado na esfera produtiva. A penetração dessas idéias no campo educacional propiciou a emergência de vozes denunciativas no interior das escolas. Assim, muitos cursos de formação em serviço foram utilizados como espaço de anunciação de uma cultura crítica no interior da profissão.

Para além das vertentes reprodutivistas, foram desenvolvidas no Brasil teorias educacionais de referência dialético-crítica, as quais apresentavam a escola como um campo privilegiado de luta social contra as dominações vigentes. No seu conjunto, as teorias de caráter progressista, apesar de reconhecerem a dominação e subordinação ideológica persistentes na relação escola-sociedade, crêem 
na capacidade crítica da razão humana e na ação emancipatória dos sujeitos históricos, portanto, em ações passíveis de transformar a realidade por meio de embates constantes contra os poderes dominantes no âmbito social (Giroux, 1986).

A inserção de teorias educacionais críticas na realidade escolar brasileira nas últimas décadas ofereceu, entre outros aspectos, contribuições para se pensar e mesmo refutar as concepções difundidas até então sobre o trabalho e a formação de professores, propiciando novas perspectivas para a pesquisa na área, bem como outros referenciais teórico-metodológicos para os projetos de formação docente em serviço.

Entre as novas proposições de formação em serviço que foram formuladas nesse contexto, tomamos como foco, aqui, aquelas que passam a conceber os professores como profissionais reflexivos, pelo motivo de essa concepção ter orientado a escolha das práticas de formação que pesquisamos, assim como pelo fato de a mesma firmar, como proposta, um novo repertório de experiência de si no que concerne à subjetividade docente na atualidade.

Grande parte dos projetos de formação docente em serviço em vigor nos dias atuais, no Brasil e em outros países, aponta para a importância de se fomentar a experiência reflexiva no professor (Alarcão, 1996; Nóvoa, 1995; Schön, 1995; Zeichner, 1998, 1995, 1993), seja pelo re-exame das crenças pedagógicas que compõem suas decisões cotidianas, seja pela narrativa de suas histórias de vida; seja pela análise dos campos de conhecimento com os quais o professor interage; seja pela problematização das finalidades e valor educativo das situações que promove; seja, em última instância, pela investigação das condições sociais e históricas que vêm atravessando a constituição de sua profissão.

Larrosa, ao analisar o enfoque reflexivo na formação do professorado, afirma que

o que se pretende formar e transformar não é apenas o que o professor faz ou o que sabe, mas, fundamentalmente, sua própria maneira de ser em relação ao seu trabalho. Por isso, a questão prática está duplicada por uma questão quase existencial e a transformação da prática está duplicada pela transformação pessoal do professor. (1994, p. 49-50)

A reflexão, nessa perspectiva, é reafirmada por vários autores como a categoria essencial da formação docente: condição tida como capaz não só de transformar a prática pedagógica do professor e prepará-lo para atender às exigências que se colocam para sua profissão na atualidade, mas, sobretudo, como capaz de modificar a pessoa do professor, constituindo-o como sujeito autônomo no mundo. Segundo Alarcão (1996, p. 174), "reflectir para agir autonomamente parece ser uma das expressões-chave no contexto educativo internacional deste final do século XX".

Nóvoa explicita os propósitos dessa modalidade quando afirma que

a formação deve estimular uma perspectiva crítico-reflexiva, que forneça aos professores os meios de um pensamento autónomo e que facilite as dinâmicas de autoformação participada. Estar em formação implica um investimento pessoal, um trabalho livre e criativo sobre os percursos e os projectos próprios, com vistas à construção de uma identidade, que é também uma identidade profissional. (1995, p.25)

Um dos primeiros estudos publicados na perspectiva de compreender o professor como um profissional reflexivo foi produzido por Schön (1995), autor cuja principal contribuição foi a de ter atribuído um novo estatuto à dimensão prática do trabalho docente, em contraposição ao modelo de aplicação técnica que reduzia as práticas pedagógicas a um espaço de acomodação dos conhecimentos oriundos da ciência aplicada.

Schön concebe a dimensão prática do trabalho profissional como um espaço 
indefinido, incerto, inconcluso, factível de produzir situações singulares, e que, portanto, necessita ser investigado e compreendido. Nessa perspectiva, a dimensão prática do trabalho profissional configura-se incompatível com a previsibilidade e o controle ensejados na lógica do conhecimento técnico.

Pelo crivo do autor, a inventividade e criatividade requeridas pelo professor no exercício de seu ofício e os discernimentos autônomos que os professores serão convocados a fazer, quando confrontados com os problemas concretos que a prática educativa confere, só poderão, contudo, verem-se ativados na consciência docente quando mediados por processos reflexivos sistemáticos - investigar, interpretar, apropriar-se de intenções.

0 professor, na abordagem de Schön, como diz Alarcão (1996, p. 18),

tem de assumir uma postura de empenhamento autoformativo e autonomizante, tem de descobrir em si as potencialidades que detém, tem de conseguir ir buscar ao seu passado aquilo que já sabe e que já é e, sobre isso, construir o seu presente e o seu futuro, tem de ser capaz de interpretar o que vê fazer, de imitar sem copiar, de recriar, de transformar. Só o conseguirá se reflectir sobre o que faz e sobre o que vê fazer.

Apesar de os estudos de Schön terem-se contraposto diretamente ao modelo teórico da racionalidade técnica, conferindo à experiência prática um estatuto epistemológico decisivo para o desenvolvimento profissional, a abordagem reflexiva por ele desenvolvida vem sendo revisitada e ampliada por outros autores mais diretamente envolvidos com a formação específica de professores: Zeichner, Contreras, Nóvoa, Geraldi, etc.

Zeichner (1998, 1995, 1993), por exemplo, problematiza a excessiva valorização, conferida por Schön, à autoridade individual do profissional para identificar e interpretar as situações problemáticas que perpassam sua prática, bem como aponta um certo reducionismo dessa abordagem, quando esta circunscreve em demasia o processo de reflexão à prática imediata, abstraindo de seu foco de análise as implicações sociais e políticas que perpassam as práticas sociais de ensino. Zeichner irá ainda defender que a atividade reflexiva não se pode manifestar por uma ação isolada do sujeito. Segundo este autor, ela exige uma situação relacional para ocorrer. A prática reflexiva deve ser considerada como uma prática eminentemente social, portanto, só passível de ser desenvolvida como uma ação compartilhada coletivamente.

Ao privilegiar os fenômenos da prática imediata e as intenções subjetivas do professor como quadro de referência para o processo reflexivo, corre-se o risco, segundo Zeichner, de promover na formação docente um modelo de reflexão que se mostra incompleto e limitado, por não estar articulado a uma análise que englobe o conjunto de significados complexos que atravessam a educação escolarizada e que estão situados para além desse quadro de referência imediato.

Um outro eixo analítico-crítico sobre a reflexividade docente é apresentado por Giroux (1986). Para ele, a atividade reflexiva deve ser operada pelo professor tendo em vista não só as problemáticas particulares que ecoam de sua experiência imediata, mas fundamentalmente aquelas que dizem respeito à cultura institucional na qual está incorporado e, em última instância, as finalidades e sentidos sociais, culturais e políticos que perpassam e orientam o trabalho escolar e sua própria prática de ensino. Segundo Giroux,

a capacidade de pensar sobre o pensamento aponta para um modo de raciocínio que tem como objetivo romper a ideologia "congelada" que impede uma crítica da vida e do mundo, sobre a qual as racionalizações da sociedade dominante se baseiam. (p. 249) 
Assim, continua ele,

é importante que os professores situem suas próprias crenças, valores e práticas dentro de um contexto, de forma que seus significados latentes possam ser melhor entendidos. Esse situar dialético, por assim dizer, ajudará a esclarecer a natureza social e política das restrições estruturais e ideológicas com que os professores se deparam diariamente. (p. 253)

De maneira geral, podemos dizer que os autores que propõem a abordagem reflexiva na formação docente apontam um esgarçamento político e cultural do objeto de reflexão enfatizado por Schön, condicionando a necessidade de alargamento do mesmo à capacidade de transformação das práticas docentes para além do compromisso exclusivo com as situações pontuais de sala de aula.

Os programas recentes de formação docente em serviço, em especial aqueles que qualificam o professor como um profissional reflexivo, apresentam-se como ocasião de convencer o professor de sua importância profissional e pleiteiam valorizar seus modos de pensar e agir, convocando- 0 a saber-se sujeito do conhecimento, gestor primordial da prática educativa que desenvolve, investigador de si mesmo, experimentador autônomo de seu ofício, centro decisório das transformações que deverá operar em sua prática cotidiana.

Não mais sendo ordenada por um continente de conhecimentos externo aos seus protagonistas, a formação em serviço circunstanciada no modelo teórico-reflexivo formula-se como uma prática segundo a qual 0 professor orquestraria sua conduta profissional via um procedimento sistemático de investigação de si.

Como essa nova inserção formativa vem atuando nas práticas concretas de formação? Que novos efeitos são inscritos na experiência docente? Quais modos de se saber professor elas promovem?
O a porte teórico-metodológico de nossa pesquisa: a psicologia institucional

Ao analisarmos, em nossa pesquisa, os ef eitos das práticas formativas vinculadas às abordagens reflexivas, identificamos um movimento de deslocamento dos objetivos que configuraram os modelos de formação docente em serviço que as precederam; ef eitos estes que sinalizaram uma dispersão, e mesmo contradição, das estratégias primeiras que operaram a organização dessas práticas. Nessa perspectiva, estaríamos teoricamente diante de um rearranjo dos propósitos estratégicos que suportaram inicialmente o dispositivo formativo, na versão "em serviço".

Propõe-se, assim, um novo enunciado, uma nova orientação para a existência de tal prática. Orientação esta que se distingue dos motivos originários responsáveis pela formulação discursiva que inaugurou as práticas de formação em serviço.

Para formularmos esse tipo de problematização, optamos por analisar a formação em serviço de professores (pautada no modelo reflexivo) não pelos registros acadêmicos, legais ou estatais que a informam e a convertem em proposta formativa na atual realidade educacional brasileira. Buscamos, ao contrário, analisá-la como ato, na concretude mesma de seu fazer particular, pela via de um de seus protagonistas centrais: o professor.

Tratou-se de investigar os meandros cotidianos desse fazer e propor uma certa visibilidade sobre o modelo formativo-reflexivo e seus efeitos na profissionalidade docente pelo crivo de um olhar institucionalista. $\mathrm{Ou}$ melhor, pelos matizes específicos de um certo conceito de instituição e subjetividade.

Cumpre esclarecer que um universo teórico específico orientou a proposição, realização e conclusões de nossa pesquisa: a psicologia institucional (Guirado, 1994, 1986; Aquino, 1996, 2000). 
Pautados na concepção de que toda instituição configura um conjunto de práticas ou relações sociais, as quais são disparadas por determinado aparato discursivo, que define a um só tempo seu acontecimento, seus movimentos e os lugares de seus protagonistas, propusemo-nos a recompor analiticamente a formação em serviço de professores como uma prática institucional, ou seja, um certo tipo de rede relacional produzida no âmbito escolar contemporâneo, acionada e mobilizada cotidianamente por um corpus de saberes, técnicas de ação ou referentes que a legitimam na sua especificidade e permanência histórica.

Assim, uma compreensão diferenciada da concretude da formação em serviço era disparada à medida que o conceito de prática (institucional) do qual partimos não se apresentava congruente com um tipo de análise compulsória segundo a qual aquilo que se diz da formação em serviço no campo das idéias (crenças, projetos e expectativas) se justaporia ou comandaria o modo pelo qual se produz cotidianamente a própria ação formativa.

Nosso pressuposto investigativo vislumbrou uma direção outra: há um nível de processualidade nas práticas concretas que, apesar de serem afetadas por determinadas redes de forças discursivas, produzem acontecimentos ímpares no movimento mesmo de sua existência. Esses acontecimentos mostram-se como efeitos criados em meio à atualização cotidiana que toda vivência relacional institucionalizada possibilita.

De acordo com o plano teórico da psicologia institucional, a permanência de determinada prática institucional, ou mesmo sua dilatação para outros territórios relacionais (por exemplo, a migração de marcas discursivas da prática formativa para a prática de ensino), serão configuradas ou não pelo poder de reconhecimento social de suas promessas, aliadas aos efeitos que essa prática institucional poderá produzir num dado contexto histórico.

Por esse aspecto, as práticas de formação de professores em serviço apresentariam, em sua plataforma existencial presente, pelo menos duas promessas, certamente mobilizadoras de um elevado grau de reconhecimento social, qualificar os saberes docentes e, por extensão, plasmar a qualificação do professor à prática de ensino por ele desenvolvida.

Promessas nada desprezíveis a julgar pela renitente desqualificação que assola a escola pública contemporânea! Contudo, vale indagar: Que efeitos instituintes essa prática vem produzindo? Esses efeitos corroboram suas promessas atuais?

Para a compreensão da idéia de "efeitos instituintes", faz-se necessário acessar o conceito de subjetividade com a qual a psicologia institucional comunga.

Os atores que protagonizam as práticas institucionais não seriam possuidores de uma substância natural a priori, ou seja, não seriam portadores de uma certa essência que os definisse de antemão, à revelia de qualquer situação relacional em que os mesmos se vissem implicados. Ao contrário de uma visão universal de subjetividade (de um sujeito- expressão de razões transcendentais), os sujeitos se definiriam concretamente ao serem situados em práticas institucionais específicas, atreladas a um contexto discursivo particular. Sujeitos constituídos no exercício mesmo das relações que vivenciam. Um sujeito em prática; sujeito-de-lugar:

Isso significa que o sujeito, nos termos da concepção institucionalista aqui defendida, só pode ser pensado na medida em que pode ser situado num complexo de lugares e relações concretas (relações sempre institucionalizadas, portanto). A noção de sujeito psicológico passa a implicar, dessa forma, o lugar institucional a partir do qual pode ser regionalizado no mundo (sujeito sempre institucional, portanto). Sujeito que só o é, de fato, como efeito de uma equação institucional que requer obrigatoriamente um outro complementar (uma relação pontual, portanto). E, sendo assim, 
que ocupa um lugar determinado em relação a outrem (parceiro de uma relação institucionalizada, portanto). E que o faz sempre de modo singular. Ou seja, está inserido em uma relação, ocupa um lugar determinado nessa relação, e dele se apodera segundo uma maneira específica, isto é, uma posição. (Aquino, 2000, p.18).

Pensemos a prática formativa (em serviço) de professores. É possível afirmarmos que ela inaugura historicamente o lugar de "professor em formação", disparando os contornos discursivos que ativarão a concretude da relação e certos estados de subjetivação docente. Produção histórica, funda-se aí também a institucionalização de novas experiências de si. Daí a subjetividade ser efeito, e não precursora.

No tempo presente, é possível afirmarmos que há um conjunto de saberes e técnicas na prática formativa que qualificam modos peculiares para a apropriação do lugar de professor em formação, os quais apresentam possibilidades modelares para sua ocupação "professor reflexivo", "professor investigativo", "professor transformador", "professor pessoa" são faces das configurações atuais inventadas desse lugar.

Os discursos teóricos informantes desses lugares, pelo crivo analítico no qual estamos sustentados, apresentam-se a nós como possibilidades contingenciais de existência docente. Isto é, essas novas conformações pautadas no modelo de formação reflexiva não foram tomadas como a maneira idealizada de ocupar 0 posto docente ou como a possibilidade de restaurar uma relação supostamente distorcida que o professor em formação constituiu consigo mesmo até então particularmente se atentássemos para a inegável violência prescritiva que o modelo corretivo de formação em serviço, gerido pela razão científica, computou à experiência docente.

Mesmo que essa nova marca subjetiva "professor reflexivo" - possa ser compreendida como potencialmente mediadora de uma expe- riência de si mais livre e autônoma, não tratamos de averiguar em nossa pesquisa os saldos positivos de seu curso no âmbito institucionalizado ou, então, de identificar suas incorreções com o intuito ingênuo de novamente ajustá-las ao itinerário preestabelecido pela instância teórica que a formulou.

Não partimos, pois, do pressuposto de que o que está em jogo nessa lógica seria a promoção de um certo espaço pedagógico que criasse oportunidades favoráveis para que a essência daquilo que por algum motivo teria se corrompido retornasse ao seu curso normal. Por último, não tomamos as práticas concretas apenas como lugares de "mediação" para que a subjetividade docente encontrasse finalmente os recursos, até então sonegados, para o pleno desenvolvimento de sua autoconsciência, autodeterminação e auto-reflexão, transformando-se supostamente naquilo que já eram desde o princípio.

As práticas institucionais concretas são, sobretudo, instâncias de produções inéditas condição esta não passível de ser evidenciada de antemão pelos discursos teóricos. Por isso, foi preciso conduzirmo-nos com um olhar menos cativo às ordenações teóricas prévias, capaz de oferecer visibilidade aos seus movimentos e construções peculiares.

Isso posto, nosso principal objetivo foi, de um lado, o de conferir uma certa visibilidade à "experiência de si" por parte dos docentes, quando conformada às modulações de professor reflexivo; produzida no próprio acontecimento concreto das práticas relacionais que a dispararam; de outro lado, de evidenciar os efeitos que essa experiência vem produzindo na subjetividade docente e quais movimentos são protagonizados no seu interior.

As vicis situdes da formação reflexiva

Os projetos e propostas de formação de professores em serviço na atualidade, vincula- 
dos a uma abordagem reflexiva sobre a profissão, vêm concorrendo como uma das ações desestabilizadoras do eixo discursivo segundo o qual as características distintivas da profissão foram anteriormente nomeadas, reconhecidas e legitimadas.

As formas clássicas quando interceptadas por uma vivência formativa de caráter contínuo, coletivo e reflexivo, parecem ver-se abaladas em sua consistência e naturalidade, ocasionando um nítido processo de realocamento das qualidades até então constitutivas e nomeáveis da profissão.

Vejamos como isso se dá nas entrevistas com os docentes, quando eles estão a viver a prática concreta da formação em serviço pautada no modelo reflexivo.

As práticas reflexivas que investigamos propõem pautas de trabalho vinculadas a um grupo de temáticas que orbitam no interior da ação pedagógica. Enfatizando um ou outro aspecto, a proposição de temáticas no espaço formativo tem como objetivo mobilizar atos reflexivos nos professores por meio de conteúdos que suscitem questões relativas à dimensão técnica, teórica e social de seu ofício.

A relevância das temáticas eleitas como conteúdo de trabalho justifica-se, no geral, pelo vínculo que elas possuem em relação às situações extraídas do processo de ensino em sala de aula. Esse vínculo representaria a própria condição de suas escolhas.

As situações de ensino migradas para 0 espaço formativo desempenham uma função primordial nessa modalidade, pelo fato de elas presentificarem 0 universo stricto sensu da ação profissional e servirem como estimuladoras concretas dos esforços reflexivos que os professores irão acionar. Assim, elas funcionariam, ao mesmo tempo, como objeto transicional entre o âmbito da sala de aula e o da formação em serviço.

Esse design de organização da prática formativa acaba por produzir um efeito insólito em seu percurso, que se configura simultanea- mente pelo afastamento dos professores dos objetos de reflexão privilegiados nas atividades de formação e pelo (re)alocamento de seus esforços e conjecturas reflexivas num outro diagrama de proposições.

Dito de outra forma, ao serem convidados a refletirem sobre situações oriundas do universo concreto de seu ofício, os professores parecem ser convocados a operar um deslizamento desses objetos, instalando suas reflexões sobre os códigos estruturantes da profissão, ou seja, sobre o lugar do professor no cenário escolar da atualidade.

Recorramos a um exemplo clarificador desse movimento para melhor apreendê-lo. Em uma situação de trabalho no interior da prática formativa, ao serem mobilizados a refletir sobre a temática "avaliação" - convidados a analisar o próprio plano avaliativo que desenvolvem, a ler textos que problematizem e fundamentem teoricamente essa temática, a investigar sobre as finalidades sociais dos processos de avaliação escolar que adotam ou produzir instrumentos e registros avaliativos para serem socializados coletivamente, os professores operam como que um desvirtuamento desses propósitos ao (re)alocarem suas reflexões em um outro plano de indagações.

Indagam-se tacitamente por que estão a fazer isso, por que precisam revisar ou (re)visitar sua prática profissional sistematicamente: A autoridade de professor já não Ihes basta? Os saberes e esforços acumulados na vivência da sala de aula não são suficientes para referendar seu desenvolvimento profissional? Por que estão eles tendo de discutir publicamente aquilo que pensam e realizam em sala de aula? Por que precisam, agora, mostrar para um "outro" aquilo que sabem fazer e que sempre desenvolveram sozinhos? Agora é preciso contar sobre seu trabalho, transformar suas ações, atuar coletivamente? Para onde foram os modelos que admitiam incondicionalmente seus fazeres? 
Essas indagações parecem ser o motivo pelo qual as falas docentes muito pouco ou quase nada dizem especificamente sobre as temáticas ou situações enfocadas nos grupos de formação, ou mesmo da suposta contribuição da formação em serviço para a qualificação de seu trabalho. São essas indagações mais fortes ou mais poderosas do que os objetos de reflexão que objetivamente Ihes são propostos (mesmo que sejam elas produzidas pela existência dos mesmos).

Se se pode pressupor que a peculiaridade do exercício reflexivo que os professores realizam é fortalecida pelas condições discursivas objetivadas no cenário das práticas formativas em serviço, pode-se supor também que 0 acontecimento cotidiano desse exercício certamente coloca em suspensão muitas das intencionalidades dos procedimentos de trabalho que orientam a organização dessas práticas, "comprometendo" os resultados imediatos que, em particular, seus mentores teóricos projetam.

Conforme os resultados de nossa pesquisa, os principais efeitos derivados da inscrição em práticas formativas, organizadas pelo modelo teórico do professor reflexivo, orbitariam em torno de três eixos centrais.

Os dois primeiros eixos localizam-se na dimensão relacional da ação docente, precisamente no deslocamento promovido pela composição dos parceiros com quem comumente os professores exerciam suas atividades profissionais. Eles passam a dividir sistematicamente seu trabalho não mais apenas com os alunos parceiros históricos de seu ofício - mas com os próprios pares. 0 "outro" agora é o próprio colega professor.

Outro deslocamento remete ao estado sob o qual, culturalmente, os professores vêm desenvolvendo suas atividades. De uma prática profissional alicerçada no isolamento, peculiar ao âmbito da sala de aula, eles passam a vivificar um modelo de profissão que é baseado na gestão coletiva e pública do ofício.
Por último, e talvez o deslocamento que parece ser mais penoso de ser incorporado: as práticas de formação em serviço arremessam a profissão docente a uma condição de permanente fluidez e revisitação de seu cotidiano, 0 que pressuporia a (re)criação e revisão contínuas das ações que realizam, do que deriva uma reflexão ininterrupta. Esse caráter mutável imputado à atividade docente se contraporia à imagem de um profissional cuja consolidação de uma sapiência a priori definiria sua característica maior.

A condição de aprendiz permanente de seu ofício, legitimada pelos eixos acima indicados, convoca o professor a criar um novo tipo de relação consigo mesmo, novos procedimentos de conduta na fabricação de si. Propõe, primordialmente, uma nova regulação ética para sua atividade profissional.

Disso decorre que, se os referenciais éticos de seu ofício estavam antes sustentados num "dever ser" que se pautava na reposição de conhecimentos avalizados pelo estatuto científico, bem como numa adequação, com maestria, dos saberes e técnicas emprestados de um "outro" pensante, o professor vinha cumprindo sua existência, de um modo ou de outro, segundo a oferta paulatina de tais saberes no percurso das aulas.

0 que se esperava do aluno era uma entrega convicta à autoridade do professor, uma fidelidade inconteste à sua oferta. E ali, o professor estava convicto de ser tudo o que deveria ser. Trocando em miúdos, tratava-se de uma ética que se modulava pelo ato virtuoso de conduzir o outro a descobrir a ordem do mundo por intermédio de uma autoridade que se pautava exatamente na não reciprocidade do vínculo entre aluno e professor, assim como no isolamento dos vínculos entre os próprios professores.

Em nossa perspectiva, há, na experiência singular da prática reflexiva da formação em serviço, um formato de profissionalidade em transição, que arremessa a profissão a um 
"dever ser" delegado a si mesma. Quase ao avesso do molde de sujeição anterior, segundo o qual seu status profissional estava codificado por um tipo de ação embalada por um modo de competência passiva e uma definição de ofício migrada da égide científica, esse novo formato incita o professor à adoção de um conjunto de condutas que o dispensa de ser um agente de repetição de modelos pré-fabricados para lançá-lo na perscrutação de si mesmo.

Uma nova ordem de codificação coloca-se para o pensar-se professor. Um novo modo de "saber de si" no fulcro da prática formativa é então disparado e conferido ao professor.

A experiência dessa vivência peculiar contemporânea, acreditamos, obriga os sujeitos-professores desse tempo a cogitarem sobre quem são diante das novas ingerências do presente sobre a profissão, quase a exigir que 0 professor dilate antigos códigos do "dever ser" da profissão e se insira no interior de seu próprio presente. Que, enfim, ele aprenda a se ver altercado pelas teorias educacionais que o legitimam como um sujeito da reflexão, autodeterminação e autonomia.

Nas vozes dos professores: não para mimetizar essa nova roupagem, como talvez ensejariam seus mentores, mas justamente para se haverem com ela.

No rastreamento da maioria das falas dos docentes em nossa pesquisa, uma pergunta parece estar sendo clamada pelo professor, a si mesmo, reiteradamente: "quem se é profissionalmente?".

Pelos efeitos que a prática reflexiva instaura nos professores, o lugar docente parece estar sendo lançado no vácuo da dúvida e da incerteza cotidianamente, fato que lança promessas de gestação inéditas no e do professor sobre sua condição na atualidade.

Se se pode dizer que o professor na prática formativa atual desvirtua o fazer reflexivo que the é proposto, esquivando-se por vezes dos objetos do "saber como", do "saber sobre" e do "saber por que" de seu ofício, é também possível dizer que o professor não escapa da afetação discursiva de um outro "dever ser", forjado nos lugares que ocupa no cenário dessa prática. Afetação que lhe incita um conjunto outro de proposições reflexivas. É a aflição de um novo paradigma de "dever ser", anunciado pela prática de formação reflexiva, que Ihe provoca um acentuado "desconforto", restando-Ihe, ao que parece, a inevitabilidade da pergunta permanente sobre quem se é/quem já não se é.

Assim, estamos diante de um sujeito que, justamente por seus paradoxos, dá mostras de seu fazer reflexivo. Uma subjetividade que, simultaneamente, já não é o "antes", mas, ao mesmo tempo, ainda não sabe seu "depois".

\section{Referências bibliográfic as}

ALARCÃO, Isabel. Ser professor reflexivo. In: supervisão. Porto: Porto Editora, 1996. p.171-189.

(org.) Formação reflexiva de professores: estratégias de

AQUINO, J ulio G. Do cotidiano escolar: ensaios sobre a ética e seus avessos. São Paulo: Summus, 2000.

Confrontos na sala de aula: uma leitura institucional da relação professor-aluno. São Paulo: Summus, 1996.

BARBIERI, Marisa R.; CARVALHO, Célia P.; UHLE, Águeda B. Formação continuada dos profissionais de ensino: algumas considerações. Cadernos Cedes. Campinas: Papirus, n. 36, p. 29-35, 1995.

CONTRERAS, J osé. La autonomía del profesorado. Madrid: Morata, 1997.

DEMO, Pedro. Formação permanente de formadores: educar pela pesquisa. In: MENEZES, Luiz C. (org.) Professores: formação e profissão. São Paulo: Autores Associados, 1996. p. 264-297. 
FORQUIN, J ean-Claude. Escola e cultura: as bases sociais e epistemológicas do conhecimento escolar. Porto Alegre: Artes Médicas, 1993.

FUSARI, J osé C. Formação contínua de educadores: um estudo de representações de coordenadores pedagógicos da Secretaria Municipal de Educação de São Paulo (SMESP). São Paulo; 1997. Tese (Doutorado) - Faculdade de Educação, Universidade de São Paulo.

A educação do educador em serviço: o treinamento dos professores em questão. São Paulo; 1988. Dissertação (Mestrado) - Faculdade de Educação, Pontifícia Universidade Católica de São Paulo.

GERALDI, Corinta M. G.; FIORENTINI, Dario; PEREIRA, Elisabete M. Trajetória de um trabalho coletivo: apontamentos para uma epistemologia da prática. In: Campinas: Mercado das Letras, 1998. p. 11-19.

; MESSIAS, Maria da Glória M.; GUERRA, Míriam D.S. Refletindo com Zeichner: um encontro orientado por preocupações políticas, teóricas e epistemológicas. In: GERALDI, Corinta M. G.; FIORENTINI, Dario; PEREIRA, Elisabete M. (orgs.) Cartografias do trabalho docente: professor(a)-pesquisador(a). Campinas: Mercado das Letras, 1998, p. 237-274.

GIROUX, Henry. Teoria crítica e resistência em educação: para além das teorias de reprodução. Petrópolis: Vozes, 1986.

GUIRADO, M. Psicanálise e análise do discurso: matrizes institucionais do sujeito psíquico. São Paulo: Summus, 1994. Instituição e relações afetivas: 0 vínculo com o abandono. São Paulo: Summus, 1986.

HARGREAVES, Andy. Profesorado, cultura y postmodernidad: cambian los tiempos, cambia el profesorado. Madrid: Morata, 1998.

LARROSA, Jorge. Tecnologias do eu e educação. In: SILVA, Tomaz Tadeu (org.) 0 sujeito da educação: estudos foucaultianos. Petrópolis: Vozes, 1994. p. 35-86.

NÓVOA, António. Formação de professores e profissão docente. In: Lisboa: Nova Enciclopédia, 1995. p. 15-33. . (coord.) Os professores e a sua formação.

SAUL, Ana Maria. Formação permanente de educadores na cidade de São Paulo. ANDE. São Paulo: Cortez, pp.63-67, 1993.

SCHÖN, Donald A. Formar professores como profissionais reflexivos. In: NÓVOA, António, (coord.) Os professores e a sua formação. Lisboa: Nova Enciclopédia, 1995. p. 77-91.

SILVA, Tomaz Tadeu. Identidades terminais: as transformações na política da pedagogia e na pedagogia da política. Petrópolis: Vozes, 1996.

SMESP - Secretaria Municipal de Educação da cidade de São Paulo. Grupos de Formação: uma (re)visão da educação do educador. Cadernos de formação - CODOT-EIA/RT002/90. São Paulo, 1990.

VEIGA-NETO, Alfredo. Michel Foucault e educação: há algo de novo sob o sol? In: e educação. Porto Alegre: Editora Sulina, 1995. pp. 9-56. . (org.) Crítica pós-estruturalista

ZEICHNER, Kenneth M. Para além da divisão entre professor-pesquisador e pesquisador acadêmico. In: GERALDI, Corinta M. G.; FIORENTINI, Dario; PEREIRA, Elisabete M. (orgs.) Cartografias do trabalho docente: professor(a)-pesquisador(a). Campinas: Mercado das Letras, 1998. p. 207-236.

Novos caminhos para o practicum: uma perspectiva para os anos 90. In: NÓvOA, António (coord.) Os professores e a sua formação. Lisboa: Nova Enciclopédia, 1995. p. 115-138.

A formação reflexiva de professores: idéias e práticas. Lisboa: Educa, 1993. 
Recebido em 31/07/2001

Aprovado em 19/11/2001

Julio Groppa Aquino é docente do Departamento de Filosofia da Educação e Ciências da Educação da Faculdade de Educação da Universidade de São Paulo, na área de Psicologia da Educação.

Mônica Cristina Mussi é coordenadora pedagógica junto à Rede Municipal de Ensino de São Paulo, e doutoranda do Programa de Pós-graduação em Educação da Faculdade de Educação da Universidade de São Paulo. 